Research article

\title{
Risk factors for acquisition of hepatitis $C$ virus infection: a case series and potential implications for disease surveillance Leland J Yee ${ }^{1,2,3}$, Heidi L Weiss ${ }^{4}$, Rebecca G Langner ${ }^{2}$, Jorge Herrera ${ }^{5}$, Richard A Kaslow ${ }^{1}$ and Dirk J van Leeuwen ${ }^{* 2}$
} \begin{abstract}
Medicine, The University of South Alabama, Mobile Alabama, 36617-2293, U.S.A
E-mail: Leland J Yee - leland.yee@lshtm.ac.uk; Heidi L Weiss - weiss@cirrus.biosccc.uab.edu;

Rebecca G Langner - rebecca_langer@gihep.uab.edu; Jorge Herrera - Jherrera@usamalil.usouthal.edu;

Richard A Kaslow - rkaslow@uab.edu; Dirk J van Leeuwen* - dvanleeu@uab.edu

*Corresponding author
\end{abstract}

Address: ${ }^{1}$ Department of Epidemiology and International Health, School of Public Health, University of Alabama at Birmingham, Birmingham, Alabama, 35294, U.S.A.;, ${ }^{2}$ Department of Medicine, Division of Gastroenterology/Hepatology (UAB Liver Center), School of Medicine, University of Alabama at Birmingham, Birmingham, Alabama, 35294, U.S.A.;, 3Infectious Disease Epidemiology Unit, London School of Hygiene and Tropical Medicine, London WC1E 7HT, United Kingdom;, ${ }^{4}$ Biostatistics Unit, Comprehensive Cancer Center, The University of Alabama at Birmingham, Birmingham, Alabama, 35294-0007, U.S.A.; and 5 Division of Gastroenterology, Department of Medicine, School of

Published: 24 July 2001

BMC Infectious Diseases 200I, I:8

This article is available from: http://www.biomedcentral.com/I47/-2334/I/8

(c) 200 I Yee et al; licensee BioMed Central Ltd. Verbatim copying and redistribution of this article are permitted in any medium for any non-commercial purpose, provided this notice is preserved along with the article's original URL. For commercial use, contact info@biomedcentral.com
Received: I5 May 200 I
Accepted: 24 July 2001

\begin{abstract}
Background: Transmission of hepatitis $\mathrm{C}$ vims (HCV) is strongly associated with use of contaminated blood products and injection drugs. Other "non-parental" modes of transmission including sexual activity have been increasingly recognized. We examined risk factors for acquiring $\mathrm{HCV}$ in patients who were referred to two tertiary care centers and enrolled in an antiviral therapy protocol.
\end{abstract}

Methods: Interviews of I48 patients were conducted apart from their physician evaluation using a structured questionnaire covering demographics and risk factors for HCV acquisition.

Results: Risk factors (blood products, injection/intranasal drugs, razor blades/ toothbrushes, body/ear piercing, occupational exposure, sexual activity) were identified in 141 (95.3\%) of participants; 23 (15.5\%) had one (most frequently blood or drug exposure), 4I (27.7\%) had two, and 84 (53.4\%) had more than two risk factors. No patient reported sexual activity as a sole risk factor. Body piercing accounted for a high number of exposures in women. Men were more likely to have exposure to street drugs but less exposure to blood products than women. Blood product exposure was less common in younger than older $\mathrm{HCV}$ patients.

Conclusion: One and often multiple risk factors could be identified in nearly all HCV-infected patients seen in a referral practice. None named sexual transmission as the sole risk factor. The development of a more complete profile of factors contributing to transmission of HCV infection may assist in clinical and preventive efforts. The recognition of the potential presence of multiple risk factors may have important implications in the approach to HCV surveillance, and particularly the use of hierarchical algorithms in the study of risk factors. 


\section{Background}

An estimated 4 million individuals in the United States and 200 million people worldwide are infected with the hepatitis $\mathrm{C}$ virus (HCV) $[1,2]$. Infection with $\mathrm{HCV}$ may lead to disabling symptoms, cirrhosis and hepatocellular carcinoma $[3,4]$ and is said to account for a significant proportion of end-stage liver disease among HCV-infected individuals (incidence of 3.1 per 1000 person-years) [5]. From 2010-2019, HCV may lead to the loss of 1.83 million years of life among those under 65, at a societal cost of billions of dollars [6].

Blood-borne transmission of HCV infection is undisputed and reflected in the prevalence of HCV among injection drug users (IDUs) and patients exposed to contaminated blood products. HCV infection has also been linked to other exposures such as intranasal cocaine use ("snorting") [7], which probably promotes passage through vessels of the nasal septum. Centers for Disease Control and Prevention (CDC) data have highlighted sexual exposure without other risk factors in 1520\% patients; two-thirds had an anti-HCV positive sexual partner $[1,8]$, but sexual practices appear to play a minor role among IDUs $[9,10,11,12]$. For a perspective on tertiary care settings we inquired about the routes of infection in referred patients. We aimed to examine the distribution of risk factors for $\mathrm{HCV}$ acquisition among patients chronically infected with $\mathrm{HCV}$ who were seeking anti-viral treatment in a tertiary care setting.

\section{Methods}

We recruited consecutive chronically infected $\mathrm{HCV}$ patients eligible for a trial of interferon-alpha and ribavirin therapy at two academic referral settings. They were selected from over 2500 patients referred to the University of Alabama at Birmingham Liver Center and the University of South Alabama Gastroenterology and Hepatology Division. Concomitant $\mathrm{HBV}$ or $\mathrm{HIV}$ infection or advanced liver disease (decompensated cirrhosis) were trial exclusion criteria. Extensive data on demographic factors as well as routes and estimated year of exposure to known HCV risk factors were gathered in an interviewer-assisted questionnaire (Table 1.A). Sexual exposure, in the present study, was defined as having at least 1 sexual contact with an individual known or suspected to have HCV. One investigator (LJY) conducted all interviews privately with assurance that data would remain separate from medical records. To enhance recall, questions were repeated with different phrasing. Standard statistical methods including calculations of prevalence, mean, median and standard deviation were applied using SAS ${ }^{\circledR}$ software (Cary, NC). This study was approved by the Institutional Review Board for Human Use of the University of Alabama at Birmingham and patients gave informed consent for the interviews.

\section{Results \\ Demographics}

Patient age ranged from 18 to 72 years with the mean \pm SD of $45 \pm 8.1$ years and a median age of 44 years. Of 148 patients, 88 (59.5\%) were males; 130 (88\%) were Caucasians and 18 (12\%) were African-Americans; 126 (85\%) had completed high school.

Table IA: Number of known risk factors in 148 patients with chronic hepatitis C infection evaluated at two Alabama tertiary care medical centers. A. Number and \% of patients exposed to each risk factor (includes multiple exposures) ${ }^{*}$

\begin{tabular}{lll}
\hline KNOWN RISK FACTOR & N (\%) & REFERENCES \\
\hline No known risk factor & $7(4.7)$ & - \\
Injection Drug or intranasal cocaine use & $71(48)$ & 7 \\
Sharing of razors and toothbrushes & $65(44)$ & 17,18 \\
Body/ear piercing & $63(42.6)$ & 7,17 \\
Recipient of blood (products) before 1992 & $62(41.9)$ & $7,19,20$ \\
Sexual exposure & $55(37.2)$ & 1,8 \\
Occupational exposure to blood & $47(31.8)$ & 21 \\
Tattooing & $25(16.9)$ & $17,22,23$ \\
Hemodialysis & $0(0)$ & 24,21 \\
Acupuncture & $0(0)$ & 25,26
\end{tabular}

\footnotetext{
*For example, if an individual has exposure to both blood products and tattooing, they are counted under "Tattooing" as well as "Recipient of blood (products) before 1992"
} 
Table IB: B. Number and \% of the I48 patients exposed to successively higher numbers of different risk factors simultaneously (frequency of multiple risk factors).

\begin{tabular}{ll}
\hline NO. RISK FACTORS & NO. PATIENTS (\%) \\
\hline No known risk factor & $7(4.7)$ \\
1 & $23(15.5)$ \\
2 & $41(27.7)$ \\
3 & $38(25.7)$ \\
4 & $21(14.2)$ \\
5 & $13(8.8)$ \\
6 & $5(3.4)$ \\
\hline
\end{tabular}

\section{Frequency of risk factors}

Most patients (80\%) reported more than one potential exposure to HCV (Table 1.A.). Only 7 individuals (4.7\%) reported no risk factor (Table 1.B.). Injection drug use was strongly associated with cocaine use (over 90\% of individuals had both) and therefore they were combined in the analysis. Among those who did not report concomitant cocaine and injection drug use, the majority reported only using injection drugs and as a result of these small numbers, an analysis of cocaine as a sole risk factor was precluded. Of the 23 persons with one risk factor, 10 (43.5\%) had received a transfusion, 7 (30.4\%) used intravenous drugs or cocaine; 3 (13.0\%) underwent body/ear piercing, 2 (8.7\%) shared razors and toothbrushes, and 1(4.3\%) had occupational exposure (needle stick, and exposures to major amounts of blood, as from work in an emergency room or administering first aid at a construction site). In no case was sexual activity reported as an independent risk factor.

\section{Risk Factors and demographic characteristics}

Patients exposed to blood products tended to be older while IDUs and patients with sexual exposure or tattoos tended to be younger (Table 32). Women reported more risk factors than men. Exposure to blood products was considerably more common in women than men and exposure to intravenous drugs and intranasal cocaine more common in men than women. Neither race nor education was associated with the number of risk factors.

\section{Prevalence of sexual exposure in conjunction with other risk factors}

Sexual exposure was reported by 14 of 54 (25.9\%) patients who had been tattooed, 33 of $53(62.3 \%)$ who shared razors/tooth brushes, and 16 of 34 (47.1\%) who received blood/blood products.

\section{Discussion}

Numerous risk factors promote $\mathrm{HCV}$ acquisition, and multiple risk factors may be present in a single individual. Infected persons cannot be dichotomized into "injection drug users" and "blood product recipients;" many in each group may have other risk factors as well. Investigators pursuing research on the origin or duration of HCV infection by sexual routes should consider multiplicity of exposure in designing studies in various settings. For example, blood contact from frequent sharing of razors could also result in HCV transmission.

The recent United States National Health and Nutrition Examination Surveys III (NHANES III), based on a random probability cluster sample, found a high prevalence of HCV among African-Americans. In contrast, our patients were recruited into an HCV study protocol after satisfying enrollment criteria, and African-Americans were under-represented relative to the Birmingham city and Alabama state populations. Less than $10 \%$ of our population was uninsured and this demographic probably more closely resembles those seen in offices of private physicians than in other groups (such as a random population sample). Because ongoing $\mathrm{HCV}$ awareness campaigns will likely bring increasing numbers of HCV patients to private physicians, those physicians should be providing appropriate advice on disease management (e.g., curtailing alcohol consumption and consideration of antiviral therapy). They may advise patients on preventing spread of the virus, but also prevent excessive anxiety in this respect. Under most circumstances transmission rates are low, but all potential sources of transmission should be discussed.

Currently in the United States for most physicians in private practice, $\mathrm{HCV}$ patients frequently first present with abnormal alanine amino transferase (ALT) levels or are found to be HCV positive as part of a routine health check for life insurance or attempt to donate blood. With the increased HCV awareness campaigns, however, it is plausible that an increasing number of patients seen in physician offices are there because they have a history of injection drug use or have received at sometime in the past blood or blood products and consequently over-represent the number of individuals with known risk factors. It is also possible that due to the exclusion criteria of our study (none were HIV or HBV positive) those with "high risk" sexual behaviors were excluded from this study. Addressing these issues was out of the scope of the present case series; however they should be addressed in future protocols examining HCV transmission in specific "high-risk" groups such as those with a high prevalence of HIV disease, or those who had HCV diagnosed in clinics for the treatment of sexually transmitted diseases. A case-control comparison of tertiary care and primary 
care clinic populations would help clarify some of these issues.

Although blood transfusion was recently reported to account for only $7 \%$ of HCV infections in the US [1], 40\% of our patients received transfusions. Many of these patients were identified in $\mathrm{HCV}$-screening campaigns that focused on recipients of transfusions before 1992, prior to the introduction of more sensitive HCV testing. In our population the older age of recipients of blood products compared with IDUs likely reflects a cohort effect due to the relatively higher risk of acquiring HCV from blood transfusion in the more distant past.

Sexual activity was not implicated as an independent risk factor even after exclusion of individuals exposed to blood or injection drugs. Other studies, including those among spouses, have suggested low sexual transmission of HCV $[13,14,15]$. Frequent sharing of razors and toothbrushes among persons who reported sexual exposure also belies the automatic assumption of sexual transmission between a dually infected couple. The assessment of risk remains particularly difficult when comparing infrequent but high-risk contact (e.g. parenteral exposure) with more frequent but lower risk exposure such as sexual activity. Even with our relatively general definition of sexual exposure, we were unable to observe any individuals with sexual contact as a sole risk factor. Inability to test all current and/or past sexual partners of individuals reporting sexual exposure precluded definitive confirmation of partner HCV status. We were therefore unable to separate those who had at least one reported sexual contact with a person suspected of having HCV from those who had at least one sexual contact with a person known to have HCV. Factors like piercing and tattooing may need to be refined into different levels of risk depending upon the setting (e.g. service by an unskilled individual versus a professional trained in proper hygiene).

The multiplicity of risk factors observed in our case series presents some important ramifications with respect to disease surveillance. Many of the disease surveillance networks employ a hierarchical algorithm to determine routes for $\mathrm{HCV}$ acquisition when multiple risk factors are present in individuals. While these hierarchies are based on the presumed likelihood of transmission per exposure, their use may potentially obscure the true contribution of "lower risk" exposures. Clearly, alternative methods of modeling risk factors should also be considered. Most importantly, attributing $\mathrm{HCV}$ acquisition to "lower risk" behaviors such as sexual exposure should be done with caution, and only after exclusion of other risk factors, and in particular, those of "higher risk," such as parenteral contact. Detailed inquiry into risk factor exposure may also increase accuracy in the ascertainment of the time of $\mathrm{HCV}$ acquisition. Accurate estimates of the duration of infection have proved useful in interpreting data on factors that influence rate of disease progression [16]. If a high number of individuals have multiple risk factors, this may provide an inappropriate picture of the true distributions of risk factors and consequently, routes of acquisition.

In summary, identification of multiple risk factors for HCV infection may be valuable for both individual patient assessment and population studies. The presence of multiple risk factors within individuals should also prompt us to re-evaluate how we interpret and present surveillance data.

Table 2: Number and \% of 148 patients with risk factors for HCV infection at two Alabama tertiary care medical centers, stratified by age, gender and race.

\begin{tabular}{|c|c|c|c|c|c|c|}
\hline \multirow[t]{4}{*}{ RISK FACTOR } & \multicolumn{2}{|l|}{ BY AGE } & \multicolumn{2}{|c|}{ BY GENDER } & \multicolumn{2}{|c|}{ BY RACE } \\
\hline & $\leq 45$ & $>45$ & Male & Female & White & Black \\
\hline & $\mathrm{N}(\%)$ & $\mathrm{N}(\%)$ & $\mathrm{N}(\%)$ & $\mathrm{N}(\%)$ & $N(\%)$ & $\mathrm{N}(\%)$ \\
\hline & $N=88$ & $N=60$ & $N=88$ & $N=60$ & $N=130$ & $N=18$ \\
\hline Blood/Blood Prod & $29(33.0)$ & $32(53.3)$ & $22(25)$ & $40(66.7)$ & $54(4 \mid .5)$ & 7 (38.9) \\
\hline Drug Use & $52(59.0)$ & $19(31.7)$ & $57(64.8)$ & $14(23.3)$ & $60(46.2)$ & II (6I.I) \\
\hline Body/Ear Piercing & $45(51.1)$ & $28(46.7)$ & $18(20.5)$ & 55 (91.7) & $61(46.9)$ & $11(61.1)$ \\
\hline Occupational & $31(35.2)$ & $16(26.7)$ & $26(29.5)$ & $21(35.0)$ & $37(28.5)$ & $10(55.6)$ \\
\hline Tattooing & $18(20.5)$ & $7(11.7)$ & $18(20.5)$ & $7(11.7)$ & $24(18.5)$ & I (5.6) \\
\hline Sexual Exposure & $42(47.7)$ & $13(21.7)$ & $62(70.5)$ & $23(38.3)$ & $50(38.5)$ & $5(27.7)$ \\
\hline $\begin{array}{c}\text { Sharing of razors/ } \\
\text { toothbrushes }\end{array}$ & $42(47.7)$ & $23(38.3)$ & $36(40.9)$ & $29(48.3)$ & $56(43.1)$ & $9(50)$ \\
\hline
\end{tabular}




\section{Acknowledgements}

This study was supported by an unrestricted grant in aid of hepatitis $C$ research provided by Schering-Plough /Integrated Therapeutics Inc. to the UAB Liver Center (D.J.vL)

We would like to acknowledge the support of the Alabama Hepatitis C Study Group: Joseph R. Bloomer, Gary A. Abrams, Brendan M. McGuire, Michael B. Fallon, Tracey Gwaltney, Emilie Barnett, Anita Johnson, and Clint Nail.

We are grateful to the CDC Sentinel Counties Surveillance System and the Vermont Hepatitis Investigation for providing their questionnaires which helped with developing our focused questionnaire.

This study was presented, in part, at the $10^{\text {th }}$ International Symposium on Viral Hepatitis and Liver Disease in Atlanta, Georgia, USA, April I2, 2000.

\section{References}

I. Alter MJ, Kruszon-Moran D, Nainan O, et al: Prevalence of hepatitis $C$ virus infection in the United States, 1988 through I 994 N Engl J Med 1999, 34 I:556-562

2. Alter MJ: The epidemiology of acute and chronic hepatitis $\mathbf{C}$ Clin Liv Dis 1997, I:559-568

3. Tong MJ, El-Farra NS, Reikes AR, et al: Clinical outcomes after transfusion-associated hepatitis C N Engl J Med 1995, 332: |4631466

4. DiBisceglie AM, Goodman ZD, Ishak KG, et al: Long-term clinical and histopathological follow-up of chronic posttransfusion hepatitis Hepatology I991, I4:969-974

5. Thomas DL, Astemborski J, Rai RM, et al: The natural history of hepatitis $\mathbf{C}$ virus infection: host, viral and environmental factors JAMA 2000, 284:450-456

6. Wong JB, McQuillan GM, McHutchison JG, et al: Estimating future hepatitis $C$ morbidity, mortality and costs in the United States Am J Public Health 2000, 90:1562-1569

7. Conroy-Cantilena C, vanRaden M, Gibble J, et al: Routes of infection, viremia and liver disease in blood donors found to have hepatitis C virus infection N Engl J Med 1996, 334:169|-1696

8. Alter MJ, Coleman PJ, Alexander J, et al: Importance of heterosexual activity in the transmission of hepatitis $B$ and non-A, nonB hepatitis JAMA 1989, 262:1201-1205

9. Donahue JG, Nelson KE, Munoz A, et al: Antibody to hepatitis C virus among cardiac surgery patients, homosexual men, and intravenous drug users in Baltimore, Maryland $\mathrm{Am} J$ Epidemiol |99|, | 34:|206-|2||

10. Thomas DL, Vlahov D, Solomon L, et al: Correlates of hepatitis C virus infections among injection drug users Medicine 1995, 74:21 2-220

II. Villano SA, Vlahov D, Nelson KE, et al: Incidence and risk factors for hepatitis $\mathbf{C}$ among injection drug users in Baltimore, Maryland J Clin Microbiol I 997, 35:3274-3277

12. Osella AR, Massa MA, Joekes $S$, et al: Hepatitis $\mathbf{B}$ and $\mathbf{C}$ virus sexual transmission among homosexual men $A m$ J Gastroenterol 1998, 93:49-52

13. Everhart JE, DiBisceglie AM, Murray LM, et al: Risk for non-A, nonB (type C) hepatitis through sexual or household contact with chronic carriers Ann Intern Med 1990, I I 2:544-545

14. Tong MJ, Lai PPC, Hwang S, et al: Evaluation of sexual transmission in patients with chronic hepatitis $\mathbf{C}$ infection Clin Diag Virol 1995, 3:39-47

15. Eyster ME, Alter H], Aledort LM, et al: Heterosexual co-transmission of hepatitis $C$ virus (HCV) and human immunodeficiency virus (HIV) Ann Intern Med 199I, I I 5:764-768

16. Yee LJ, Tang J, Herrera J, et al: Tumor necrosis factor gene polymorphisms in patients with cirrhosis from chronic hepatitis C virus infection Genes Immun 2000, I:386-390

17. Mele A, Corona R, Tosti ME, et al: Beauty treatments and risk of parenterally transmitted hepatitis: results from the hepatitis surveillance system in Italy Scand I Infect Dis 1995, 27:44I-444

18. Tumminelli F, Marcellin P, Rizzo S, et al: Shaving as potential source of hepatitis C virus infection Lancet 1995, 345:658

19. Alter HJ, Purcell RH, Shih JW, et al: Detection of antibody to hepatitis $C$ virus in prospectively followed transfusion recipients with acute and chronic non-A, non-B hepatitis $N$ Engl I Med $1989,321: 1494-1500$
20. Aach RD, Stevens CE, Hollinger FB, et al: Hepatitis $\mathbf{C}$ virus infection in post-transfusion hepatitis $N$ Engl J Med I99|, 325:I3251329

21. Alter MJ, Hadler SC, Judson FN, et al: Risk factors for acute nonA, non-B JAMA 1990, 264:2231-2235

22. Sun D, Zhang F, Geng $Y$, et al: Hepatitis $\mathbf{C}$ transmission by cosmetic tattooing in women Lancet 1996, 347:54 I

23. Kaldor JM, Archer GT, Buring ML, et al: Risk factors for hepatitis $C$ virus infection in blood donors: a case-control study Med J Aust 1992, I 57:227-230

24. Sandhu J, Preiksaitis JK, Campbell PM, et al: Hepatitis C prevalence and risk factors in the northern Alberta dialysis population Am J Epidemiol 1999, I50:58-66

25. Mansell C, Locarini SA: Epidemiology of hepatitis $\mathbf{C}$ in the east Semin Liver Dis. 1995, I5:15-32

26. Kioysawa K, Tanaka E, Sodeyama $T$, et al: Transmission of hepatitis $\mathbf{C}$ in an isolated area in Japan: community-acquired infection Gastroenterology 1994, 106:1596-1602

\section{Pre-publication history}

The pre-publication history for this paper can be accessed here:

http://www.biomedcentral.com/content/backmatter/ 1471-2334-1-8-b1.pdf

Publish with BioMed Central and every scientist can read your work free of charge

"BioMedcentral will be the most significant development for disseminating the results of biomedical research in our lifetime." Paul Nurse, Director-General, Imperial Cancer Research Fund

Publish with BMC and your research papers will be:

- available free of charge to the entire biomedical community

- peer reviewed and published immediately upon acceptance

- cited in PubMed and archived on PubMed Central

- yours - you keep the copyright 